\title{
La cohesión social en un mundo globalizado
}

\author{
Social coherence in a global world
}

\author{
Boris I. Yopo*
}

El proceso de globalización que ha vivido el mundo en los últimos quince años tiene dos caras o facetas. Por una parte, ha generado un impulso económico sin precedentes, y en algunas áreas del mundo (particularmente Asia) ha generado empleo y una disminución importante en los niveles históricos de pobreza. Pero por otra parte, si se observan los procesos electorales que han tenido lugar en el mundo en los últimos años, aunque con sus particularidades, casi todos parecen tener también un denominador común: las inseguridades que sienten las sociedades contemporáneas frente a los desajustes, transformaciones y desigualdades que se han generado a partir de la apertura de las economías a la competencia glo$\mathrm{bal}^{1}$.

Cuando casi simultáneamente el Papa Benedicto II, el Director del FMI, y el Presidente de la Reserva Federal de
Estados Unidos hablan públicamente de los riesgos que puede traer la creciente brecha de desigualdad en el desarrollo económico global, es momento de repensar la relación entre las dinámicas económicas y los procesos sociales que acompañan a este fenómeno. La precariedad del empleo, la disminución de los salarios, el desmantelamiento de las redes de protección social, y la competencia «desleal» que proviene de regiones donde se pagan salarios de subsistencia, son los factores más citados por aquellos sectores que rechazaron la nueva constitución europea en Francia y Holanda, que dieron el triunfo a los demócratas en las últimas elecciones legislativas de Estados Unidos, y que han instalado a gobiernos «anti-neoliberales» en casi toda América Latina.

En un reciente informe sobre la economía mundial, The Economist seña-

Profesor del Instituto de Estudios Internacionales.

1 Para una discusión reciente sobre los efectos de la globalización, ver el artículo de Kenneth Scheve, «A New Deal for Globalization», en Foreign Affairs, julio, 2007. 
laba por ejemplo, que en los últimos cinco años el salario medio de un trabajador norteamericano ha caído un $4 \%$ pese a que la productividad laboral se ha elevado un $15 \%$ en el mismo período. Por otra parte, esta misma fuente indica que el $1 \%$ más rico de ese país, incrementó de $8 \%$ a $16 \%$ su participación en el ingreso total en los últimos quince años ${ }^{2}$. No es extraño entonces, que aun el columnista conservador del diario The New York Times en un artículo titulado «Karl's New Manifesto» rememorase hace algún tiempo a Marx, al describir las desigualdades que está produciendo el capitalismo en su versión norteamericana ${ }^{3}$.

La pregunta central que surge entonces hoy en muchos debates y conferencias internacionales es cómo se hace para competir como país en una economía globalizada, y al mismo tiempo asegurar que los beneficios de esta inserción global beneficien de manera más extensiva y permanente al conjunto de la población.

A este respecto, cabría decir dos cosas iniciales: el crecimiento económico aunque indispensable no es suficiente si no existe capacidad institucional para «nivelar las condiciones de origen» que son las que determinan las posibilidades de acceso de las personas a las fuentes que generan esta desigualdad inicial. Analizando el caso asiáti- co por ejemplo, el economista jefe del Banco Asiático de Desarrollo, Ifzal Ali, señalaba que por cada punto de crecimiento en Asia entre 1990 y 2002, la pobreza había declinado en dos puntos, es decir el doble, pero advierte al mismo tiempo que todavía hay 700 millones de asiáticos que viven con menos de un dólar al día, y que de mantenerse el acceso extremadamente desigual a las oportunidades, la eliminación de la pobreza no se veía en el horizonte ${ }^{4}$.

Segundo, contrariamente a lo sostenido por algunos economistas ortodoxos, para que el mercado sea funcional a una política que propenda a expandir las oportunidades, se requiere una institucionalidad fuerte que corrija las distorsiones que este produce, y que además, asegure que efectivamente haya libre competencia entre los agentes económicos que participan en él...

En su reciente libro State Building: Governance and World Order in the 21st Century, Francis Fukuyama critica por ejemplo, la «revolución ReaganThatcher» por haber promovido un virtual desmantelamiento del Estado en los países en desarrollo, ignorando que los principales problemas hoy tienen que ver directamente con la existencia de Estados débiles o colapsados: el sida, hambrunas, terrorismo, refugiados, conflictos étnicos, etc. Incluso cita a

\footnotetext{
Ver «Survey of the World Economy», The Economist, 16 de septiembre de 2006. David Brooks, «Karl's New Manifesto», The New York Times, 29 de mayo de 2005.

4 Ifzal Ali, «In Asia More Equality Means Less Poverty», International Herald Tribune, 26 de agosto de 2004 .
} 
Milton Friedman, quien reconoció antes de fallecer, que si ahora pudiese dar un consejo, sería que la existencia de «una institucionalidad sólida es más importante que la privatización de bienes $»^{5}$.

Ahora bien, en algunas circunstancias esto podría implicar más gasto público, especialmente si se trata de «nivelar» las oportunidades para los grupos más rezagados de una sociedad. Y esto no tiene porqué afectar la competitividad de un país. El columnista del Financial Times Martin Wolf, en su reciente libro Why Globalization Works, demuestra con gráficos que no hay ninguna correlación inevitable entre estas dos dimensiones, y que lo que realmente importa es si se están usando eficientemente los mayores recursos disponibles ${ }^{6}$.

Por otra parte, la discusión sobre las mejores formas de organización social para generar crecimiento y riqueza tienen que ver también con el tipo de sociedad en que se quiere vivir. Países europeos por ejemplo, han defendido su modelo de desarrollo versus el norteamericano, y citan algunos casos exitosos como los de Suecia y otros Estados nórdicos que han logrado desarrollar economías altamente competitivas, sin las «desigualdades sociales del modelo norteamericano».

Efectivamente, estos países, sin cam- biar la «esencia» del modelo de «bienestar social», lograron adaptar este a las condiciones de la nueva economía global, y han conseguido altos indicadores de crecimiento, innovación tecnológica, productividad laboral, tasas de empleo, etc. Dinamarca por ejemplo, introdujo en 1994 la flexibilidad laboral y salarial, pero en un esquema de generosos beneficios de desempleo y política pública orientada a capacitar y asistir a los desempleados, para así conseguir una pronta reinserción laboral. Esto ha creado un círculo virtuoso de flexibilidad para los empleadores, y de seguridad para los asalaria$\operatorname{dos}^{7}$.

Además, como reconoció The Economist hace algún tiempo al analizar el tema de la competitividad de las economías, si bien la economía norteamericana muestra una alta productividad e innovación, debido a la precariedad de sus redes de protección social se encuentra menos preparada para afrontar los «shocks» de eventuales crisis económicas mundiales. No es casual entonces que en este período preelectoral en Estados Unidos, temas importantes que empiezan a ocupar la agenda pública tengan que ver con reinstalar la cobertura universal de salud, mejorar los planes para combatir la pobreza dura, y proteger a los trabajadores de los desajustes que trae la

5 Francis Fukuyama, State Building: Governance and World Order in the 21 st. Century, Yale University Press, New York, 2006.

6 Martin, Wolf, Why Globalization Works, Praeger Publishers, Chicago, 2006.

7 Jeremy Rifkin, "Capitalism's Future on Trial», The Guardian, 22 de junio de 2005. 
mayor competencia de los nuevos gigantes asiáticos, como China y la India $^{8}$.

Sin embargo, no se trata de andar buscando «modelos» por el mundo, como se ha hecho con alguna regularidad en América Latina. Pero sí de considerar estos ejemplos como una referencia útil para tener la imaginación y flexibilidad necesarias al concebir nuevas políticas que mejoren la equidad e inclusión sociales en momentos en que la competencia global, sin regulaciones, polariza y genera tensiones al beneficiar de manera desproporcionada a quienes tienen el capital humano y social, los recursos y las redes necesarias para hacer uso de las oportunidades que se abren con la globalización, pero que relega a quienes carecen de estas habilidades y medios para adaptarse a la nueva economía global.

Los países nórdicos de Europa, y casos recientes de desarrollo exitosos, como Irlanda, Australia, Nueva Zelanda, tienen en común haber adaptado (sin modificar la esencia) el «modelo de bienestar social» a las nuevas condiciones que impone la competencia global, combinando flexibilidad y seguridad en el mercado laboral, con innovación tecnológica, reformas educativas y capacitación técnica, en un marco que mantiene la protección social y la intervención del Estado para corregir las distorsiones que generan las «imperfecciones» del mercado.

Así, estos países han logrado tener al mismo tiempo economías competitivas y solidarias, experimentando entonces, de manera menos traumática, el impacto de las grandes transformaciones globales en sus sociedades y economías. Estas experiencias muestran en definitiva que emprendimiento y protección social no son conceptos antagónicos, y que es posible generar un «circulo virtuoso" que integre los nuevos desafíos, pero con menos incertidumbre?

Es esto en definitiva, lo que dará sustentabilidad al actual proceso de globalización en el largo plazo. La creciente conectividad global es un proceso irreversible, pero la apertura de las economías a la competencia global no lo es. En el pasado, otros momentos de globalización que se creían irreversibles, colapsaron como resultado de grandes desajustes económicos y degeneraron en guerras y conflictos mundiales. Es necesario revisar la historia para impedir que ello vuelva a suceder.

8 «Inequality and the American Dream», The Economist, 17 de junio de 2006; Paul Krugman, "Our Sick Society», The New York Times, 5 de mayo de 2006.

9 Nick Clegg, «Why Europe Should Look Within for Inspiration», Financial Times, 30 de marzo de 2005. 